\title{
Urban Public Transport financial Supporting Policies Study in China
}

\author{
Sa $X u^{1, a}$ \\ ${ }^{1} 509$ Room, China Urban Sustainable Transportation Research Center(CUSTReC) \\ China Academy of Transportation Sciences, MOT, P.R.CHINA (CATS), 240\# Huixinli, Chaoyang \\ District, P.R. China \\ axusa_custrec@163.com
}

\begin{abstract}
Keywords: Urban Public Transport, Financial Policies, Subsidies
Abstract. With the rapid development of Chinese cities and economy, public transport demand is increasing rapidly, urban public transport priority development has become the focus of the China's transportation development policy. However, Chinese public transport supply and the huge demand for public transportation can't match. China has not established a sustainable financial support mechanism for urban public transportation. Urban public transportation infrastructure investment and operating loss are also needed to be compensated by the central and local government. In this paper, on the basis of analyzing the current situation of the development of urban public transportation in China, from the standpoint of legislation, the local financial support system, the central financial support system and cost-price linkage mechanism, a sustainable subsidy mechanism of Chinese urban public transport should be established in order to further promote the development of Chinese urban public transport.
\end{abstract}

\section{Introduction}

At present, with the rapid growth of national economy, China is in the key period of urbanization being accelerated, with an important characteristic of the urban mechanization standard being rapidly improved. The progress of urban sustainable development is heavily restrained by the confronted serious problems, such as the traffic congestion, environmental contamination, energy crisis, associated with unconstrained growth in cars crowding out other transport modes on urban roads and in city space.

Urban transit is with some unique advantages in road space using, environmental protection and energy saving, comparing with other transportation modes. Therefore, transit priority is an alternative solution to the urban transport problems. Urban transit ought to be under the government's public utility management. From the nomology aspect, urban transit should be contained in the government procurement public services, as the public health care and public education.

\section{Status of Chinese Urban Transit}

(1)Stagnant Situation Is Expected to Be Radically Transformed

Currently, the mode split rate of the urban transit in China is still low, nationally no more than $20 \%$. And in the cities with a population of no more than one million, the rate is approximately $10 \%$, which is far lower than that (50\% 70\%) of the overseas cities of the same scale. It is estimated that the mode split rate of the urban transit in China cities with a population of $1 \sim 3$ million is $20 \%$, with a population of more than 3 million $30 \%$.

Travel speeds are slow. The average travel speeds by different mode in Beijing are as follows, transit $9.1 \mathrm{~km} / \mathrm{h}$ (average distance $9.5 \mathrm{~km}$ and time 62.5 minutes), rail 12.9km/h (14.5 and 63.7), car $21.1 \mathrm{~km} / \mathrm{h}$ (14km and 39.8 minutes).

The transfer convenience is rare. Taking Beijing as an example, the average transfer distance is over $350 \mathrm{~m}$, and that is over $500 \mathrm{~m}$ for $30 \%$ of the passengers, $1 \mathrm{~km}$ for $16 \%$. The walking time to and from the transit station is 7.59 minutes and 8.41 minutes respectively.

(2) Urban Public Supply and Demand Need to Be Well Matched 
In 2009, the total urban resident trips are approximately 600 billion, $13 \%$ of which is by transit. At an average annual growth rate of $6 \%$, equivalently 0.301 billion trips per day, the number is expected to reach 110 billion by 2015, and 951.7 billion by 2020, of which 270 billion by transit, account for $27 \%$ of the total.

The carrying capacity of the urban transit in China is too poor to meet the rapid growing transportation demand of the residents. Comparing with that in overseas similar cities, the trip structure by transit mode needs further restructuring and optimization. The trip structures in some similar cities both home and abroad are as follows[1].

(3) Financial Support Policy for Urban Transit Investment Needs Further Improvement

Under the current system, the fiscal power and administrative authority of the local governments are responsible for the development of the urban transit. Among the resources for construction of and subsidy to urban transit, only the fuel subsidies come from the central government, the rest is supplied by the local governments. It is urgent to allocate special funds and expand investment channels for the urban transit development[2].

Being lack of unanimous understanding of the urban transit and inconsistent in economic development levels, the municipal governments give more subsidies to the urban transit when they have strong much financial power, less when weak.

Especially, the central cities, such as Beijing, Shanghai, Shenzhen, need urgently the fund to enhance urban transit capacity, because they are under high pressure of traffic, with the rapid development of society and economy, and taking the front row in city and population scales in China. And the local cities can not well solve their urban transit problems with the narrow investment channel, because the local municipal authorities are always under great pressure of weak financial power, accentuated by the unbalanced regional economic development and different demand levels for transit.

\section{Development Goals of China Urban Transit}

To make transit-oriented urban development strategies, and coordinate the relationship between transit, cars and other modes; to reasonably subdivide urban transit structure and construct diversified transit service system based on the city scale; to strengthen the transit planning regulation, increase the investment on transit infrastructure construction for more transit supply and better transit service; to strengthen policy guidance, propaganda and education, so that transit mode will be the priority trip selection of the residents and the transit mode split rate will improved[1].

(1) To Build Transit Construct Based on City Scale

In the cities with a population of more than 10 million, rail transit operation network will be formed, which will cover the central areas, and the conventional bus transit will act as the extension and supplement of rail transit network trips. The transit mode split rate is expected to be no less than $60 \%$ in the following 5 years.

In the cities with a population of between 3 and 10 million, rail transit network will be constructed and be the backbone of the urban transport system, of which the conventional bus transit network should act as the principal part. The transit mode split rate is expected to be no less than $40 \%$ in the following 5 years.

In the cities with a population of between 1 and 3 million, emphasis will be put on the construction of ground transit system and the joint development of BRT and network.

(2)To Accelerate the Construction of the Integrated Passenger Transfer Hubs and Stations

To construct integrated passenger transfer hubs, well arranged and reasonably located, connecting the transport inside and outside cities; to accelerate the construction of urban transit parking lots, terminal stations and bus bays based on the land use priority; to construct auxiliary transfer infrastructures and service facilities for the motor and non-motor vehicles. 


\section{Conclusions: Pubic transit financing supporting policies}

(1)Put forward Urban Transit Rules, for legal support to urban transit subsidy

The Urban Transit Rules at the national level, for which the public comment period has finished, should be put forward as soon as possible. It is the first national transit law and has ensured principles such as "Urban transit is public welfare", "City government should put transit in the first priority among different travel modes", "City government should provide full support in budget, tax, finance, land use, infrastructure, etc. to encourge the pubilc to use transit .”, "The development of urban transit should be lead and planned in entirety by the government” This can stablize and strenghten the transit priority policy at nationalwide, as well as provide more subsidy and other supports to urban transit sector.

(2)The national government set up urban transit development founding (UPTDF), the major source of which is from fuel surcharge and vehicle purchase tax

The financial source for urban public transport development special fund is mainly from fuel surcharge and vehicle purchase tax. The fund targets at providing assistance for national transit travel subsidy, high capacity public transport, major passenger traffic terminal, urban public transport informationization, energy-saving and emission-reduction, areas with high public transport infrastructure construction demand, financial difficult areas, safety and security construction, major technology innovation projects, integration of urban and rural public transportation projects.

(3)The local government establishes the UPTDF which principal source are fees related with private car using

Giving priority to urban public transportation development, the private car using is reasonably programmed at the same time. to reduce traffic jam. Many international cities, such as London, Zurich, Copenhagen, Singapore, Tokyo, implemented the policies and measures to entice people out of their cars, such as reducing car-park space in traffic jam areas, increasing car using fees and parking fee by a big margin in city central area, imposing car parking fee and a license fee, fuel surcharge usage fees of urban roads. Etc.

We should study on the economic policies in China which are acceptable and practical, on controlling private car using to increase the cost of private cars' owning and using and implement them steadily. The policies can be to adjust Car Park Charging, to implement Traffic Jam Area Charging and others related with private cars' exterior cost, by which the problem of lack of urban public transportation development fund can be solved.

The fees mentioned above will be specially used to develop urban transit, to improve the service quality of urban transit. Specially the Local UPTDF can be used for the urban transit subsidy, like urban transit fare reduction subsidy, special categories of passengers welfare subsidy, compensation for government imposed services. It also can be used to prove urban transit infrastructure facilities, like construction of stops, parking station, bicycle traffic project, public transport interchange facilities in large communities.

Besides, urban economy development and urban land value are all enhanced largely by urban transit development. Local government should collect partial money from land-transferring fees, urban maintenance and construction tax, fees added of utilities as the resources of UTDP.

(4)To set up a tied mechanism of cost-fare-subsidy based on the transit service quality[3,4]

To guarantee sustainable development of the urban transit operators' and subsidies, we have already been in the process of research on the tied mechanism of cost-fare-subsidy based on the transit service quality. The transit fare price should be decided on the basis of considering the cost, passengers' consumption level, fiscal and the operator's margin. Besides, there should be a Price Adjustment Mechanism which can show the fluctuations of cost in time and adjust the price level properly. Moreover, the subsidies are partially decided by the result of service quality assessment, which can guarantee the urban transit operators providing efficient service.

(5)To Establish Central and Local Financial Guarantee System for Transit Subsidies[5] 
Under the condition of market economy, it is necessary to strengthen urban transit management, and to shape a long-term mechanism of urban transit subsidy in China. The central level and local level subsidies are both necessary.

The central government should be responsible for financing the infrastructure construction and the intelligent transport promotion in some comprehensive and critical hub station, etc.. Subsidies for more positive externalities to promote the performance of macro-economy in China. The present fuel subsidy nowadays is not sufficient for the positive externalities public transport. This kind of subsidy instrument should be optimized. Meanwhile, other subsidy instruments should be innovated to incent the public transport operators in the respects of energy-saving, more positive externalities, etc..

The subsidies from local level government Subsidies should involve subsidies as below:

- Subsidies for the implemented low level of transit fares,

-Subsidies for construction of transit stations, guideboards, parking lots, bus lanes, BRT, ITS, hubs exhibiting promotion of TOD etc., and depreciation of those facilities and vehicles

-Subsidies for the transit service for special groups, such as the old, the students, the soldiers, the disabled, who could get preferential treatment when using transit

-Subsidies for the government procurement of transit service, such as service for large social action, disaster relief, emergency rescue, etc..

-Subsidies to partly help solve the remained problems occurred during the transit reform

\section{Acknowledgements}

This work was financially supported by the Volvo Research \& Educational Foundations (VREF) "Research on Chinese Urban Public Transportation Sustainable Subsidy Policy"(CoE-2005-3).

\section{References}

[1] Jingjing Shan: Study on low-fare Beijing Public transport from the standpoint of Public Consumption[J]. Cooperative Economics and Technology, 2009 (4):106-107(In Chinese).

[2] Pu Qian: To Establish the Urban Public Transport Subsidy Mechanism [J]. Urban Public Utilities, 2008(2):4-7(In Chinese).

[3] Sa Xu: Subsidy Method for Chinese Urban Public Transportation[R]. China Academy of Transportation Sciences, MOT, P.R.CHINA (CATS), 2013(In Chinese).

[4] Xiangjing Xin: Linkage mechanism research of urban public transportation cost price subsidies [J]. Accounting communication, 2012(14):53-55(In Chinese).

[5] Xiao Peng, Yulin Jiang, Quanhou Zhao, Sa Xu: Public Financial Supporting System for Chinese Urban Public Transportation priority Development[R]. China Academy of Transportation Sciences, MOT, P.R.CHINA (CATS), 2012(In Chinese). 